more research from both medical and social science perspectives (Lee \& Yu, 1995).

It has been estimated that not less than $5 \%$ of people in China practise qigong. The proportion of such people who develop psychiatric complications remains unknown but is likely to be very small. None the less, China has a population of 1.3 billion. The estimate that 600 people received psychiatric treatment for qigong-induced mental disorder cannot automatically be assumed to represent an abuse of psychiatry. China is a huge, heterogeneous and rapidly transforming country in which the standard of psychiatry varies widely from region to region. So the possibility of unethical psychiatric practice certainly exists. Additionally, in the current period of market reforms, the Chinese Government has withdrawn central funding for health care, and hospitals are forced to generate an increasingly large part of their own incomes. As a result, China is in the paradoxical position of having an inadequate number of psychiatric beds, yet at the same time a large number of beds that are unoccupied because families cannot afford to send patients to hospitals on a fee-for-service basis (Lee \& Kleinman, 2000).

As a China researcher who can be critical of recent social and moral changes in the country, I feel obliged to point out that even if unethical psychiatric practice existed in China (as it does in the USA, UK, or elsewhere), it would simply not be on the scale seen in the former Soviet Union. I must conclude that the views of Lyons and others who reach similar conclusions (e.g. "Contortions of Psychiatry in China", New York Times, 25 March 2001) are premature and even dangerous, and beg the question of who really is politicising psychiatry in China. As an international leader in psychiatry, the World Psychiatric Association must undertake its review of the accusations against Chinese psychiatrists prudently.

Lee, S. (1996) Cultures in psychiatric nosology: the CCMD-2-R and international classification of mental disorders. Culture, Medicine, and Psychiatry, 20, 421-472.

_ \& Yu, H. (1995) The evaluation of qigong induced mental disorder as a Chinese culture-bound syndrome (in Chinese). Archives of Psychiatry, 4, 222-225.

—\& Kleinman, A. (2000) Grave new world: is reform disease or cure for China's mentally ill? Harvard China Review, 2, 72-75.

Lyons, D. (200I) Soviet-style psychiatry is alive and well in the People's Republic (letter). British Journal of Psychiatry, 178, 380-381.

S. Lee Department of Psychiatry, II/F, Prince of Wales Hospital, Shatin, Hong Kong

\section{Lest we forget, again}

May I comment upon and add to the recent paper by Jones \& Wessely (2001).

The deployment of psychiatrists in both World Wars was a constant battle waged against ignorance and prejudice (Shephard, 2000), even when as well prepared and aware as the Americans prior to the First World War (Salmon, 1917). It appears that each generation is doomed to relearn the lessons of combat psychiatry.

Although the authors describe its effects, they make no mention of combat psychiatry's touchstone, 'evacuation syndromes'. Described by the Russians in 1904-1905 they revealed what happened when a soldier's social role is replaced by that of a patient, i.e. the 'fixation' of symptoms (Awtokratow, 1907). A similar type of problem may be seen in civil practice (Hadler, 1996).

Combat-related military diagnostic practice has been, and remains, problematic (especially in research) as the aim is to minimise stigma, normalise the experience where possible and positively emphasise recovery (McCarroll et al, 1993). During combat, military medical officers have the moral and ethical dilemma that their 'patient' is the organisation rather than the individual and is affected by whether they relate predominantly to the majority (civilian) or minority (military) culture. While doctors may feel compassion towards those who break down, evacuation may mean the lives of those who remain behind are made more uncomfortable and dangerous - hardly surprising therefore that peers or commanders may not view breakdown sympathetically.

Acute or post-combat psychological reactions are multi-factorial in aetiology. Their genesis is the product of an interaction between the individual, the event, the environment (before, during and after) and the culture from which individuals hail and to which they return. Hence, rates may range from 0 to $100 \%$ in the same theatre of operations (Noy et al, 1987). Although there is a direct relationship between physical and psychological casualty rates, this relationship may be stated more bluntly: winners get fewer psychological casualties.

The word 'fatigue' is used loosely by Jones \& Wessely. During the discussion of the Normandy offensive they state that "high percentages were also a function of widespread battle fatigue in soldiers who had already fought in North Africa ...."; this should read war-weariness. In 1939 , unlike 1914, there was no euphoria about the impending war and throughout the Second World War there was a feeling that "I've done my bit, now it's time for someone else to do their's" - this certainly seemed true in experienced veterans recalled to duty in Normandy and Korea.

Although often forgotten, the lessons of military psychiatry are as true today as in 1904-1905. Military psychiatrists cannot escape the social consequences of their labelling behaviours - perhaps this is the current combat psychiatry lesson to be forgotten!

Awtokratow, P. M. (1907) Die Geisteskranken im russischen Heere während des Japanischen Krieges. Allgemeine Zeitschrift für Psychiatrie, 64, 286-319.

Hadler, N. M. (1996) If you have to prove you are ill, you can't get well: the object lesson of fibromyalgia. Spine, 2I, 2397-2400.

Jones, E. \& Wessely, S. (200I) Psychiatric battle casualties: an intra- and interwar comparison. British Journal of Psychiatry, 178, 242-247.

McCarroll, J. E., Orman, D. T. \& Lundy, A. C. (1993) Differences in self- and supervisor-referrals to a military health clinic. Military Medicine, 158, 705-708.

Noy, S., Belenky, G. \& Solomon, Z. (1987) Battle stress, morale, cohesion, combat effectiveness, heroism and psychiatric casualties: the Israeli experience. In Contemporary Studies in Combat Psychiatry (ed. G. Belenky), pp. II-20. New York: Greenwood Press.

Salmon, T.W. (1917) The care and treatment of mental diseases and war neuroses ("shell shock") in the British Army. Mental Hygiene, I, 509-547.

Shephard, B. (2000) A War of Nerves. Soldiers and Psychiatrists 1914-1994. London: Jonathan Cape.

I. P. Palmer Department of Psychiatry, Royal Defence Medical College, Fort Blockhouse, Gosport, Hampshire POI2 2AB, UK

Authors' reply: Constructive criticism from a collaborator is always welcome. Palmer is right to point out the importance of evacuation syndromes, although sadly no psychiatric casualty statistics are readily available from the Russo-Japanese war. $\mathrm{He}$ also properly points out the broader cultural environment in which psychological casualties are framed. However, the purpose of our paper was to suggest that these factors shape the expression of these disorders rather than their incidence, which is largely determined by battle intensity irrespective of place or period. This explains why rates may vary considerably in the same theatre of operations as we demonstrated (Jones \& Wessely, 2001, Table 4). Although it is generally true that "winners get fewer 
psychological casualties", this does not apply to Pyrrhic victories. Ultimately, the French defeated the Germans at Verdun in December 1916 but suffered greater casualties, many of which were treated in their newly established 'neurological' centres set up close to the front line (Roudebush, 1995).

We cannot accept that the term 'fatigue' was misused. In fact, the War Office report (1951) from which we quoted used both "exhaustion" and "fatigue" to describe servicemen suffering from acute combat stress (War Office, 1951: 7). It is not true to say that all of these men were simply 'war-weary' as Palmer claims. A detailed analysis of 153 cases admitted to 30 corps's Exhaustion Centre in the week ending 18 June 1944 showed that $47(30.7 \%)$ were recently enlisted replacements (Wishart, 1944). It is likely that these men had not been given adequate time to become fully assimilated in their units and, without the protection of group cohesion, rapidly broke down. Equally, UK reservists recalled to fight in Korea, who might be presumed to have been war weary, often recorded lower rates of cold injury (an index of morale) than their younger and less experienced counterparts (Watts, 1952).

Jones, E. \& Wessely, S. (200I) Psychiatric battle casualties: an intra- and interwar comparison. British Journal of Psychiatry, 178, 242-247.

Roudebush, M. O. (1995) A battle of nerves:

hysteria and its treatment in France during World War I, pp. 88-90. PhD thesis, University of California at Berkeley.

War Office (195I) Psychiatric Disorders of Battle. London: War Office.

Watts, J. C. (1952) Cold injury in Korea. Journal of the Royal Army Medical Corps, 98, I-7.

Wishart, J.W. (1944) Psychiatric reports, Normandy. London: Wellcome Institute for the History of Medicine archive RAMC 408/3/3.
E. Jones, S. Wessely GKT School of Medicine, Department of Psychological Medicine, 103

Denmark Hill, London SE5 8AZ, UK

\section{An alternative to interruption of treatment in recurrent clozapine- induced severe neutropenia}

The use of clozapine is limited by the potential for haematological adverse effects (Young et al, 1998). Facing the occurrence of neutropenia the generally accepted attitude is to interrupt the treatment, and rechallenge with clozapine is usually avoided. We report the case of a woman with schizophrenia who was re-challenged with clozapine 10 years after she had developed severe neutropenia under clozapine, and who has been kept on this medication despite the occurrence of three episodes of severe neutropenia by using granulocyte and macrophage colony stimulating factor (GM-CSF) repeatedly.

Miss M. was first admitted in 1988 for an acute psychotic episode. After failing to respond to two standard neuroleptics she was started on clozapine. Her clinical situation improved markedly. The treatment was interrupted after 6 weeks when she developed severe neutropenia. Despite various treatments she continued to hallucinate and be delusional over the next 10 years. In 1998 she was admitted because of the aggravation of her clinical state. During her 8-month hospital stay, olanzapine and sertindole, alone and combined with benzodiazepines, antidepressants and mood stabilisers, were tried without improvement. Clozapine was reintroduced. The clinical situation improved markedly and the patien left the hospital 3 weeks later. She eventually went through three episodes of severe neutropenia at weeks 10,35 and 48, that were all successfully treated with one subcutaneous injection of GM-CSF. The clozapine dose had been gradually increased up to $450 \mathrm{mg} /$ day by week 40 .

The use of colony stimulating factors has been reported as a means to continue treatment despite the occurrence of severe neutropenia. However, in the case described the cytokines had to be administered only once and the dosage of clozapine was relatively low (Sperner-Unterweger et al, 1998). In the present situation, the treatment was continued despite three successive episodes of severe neutropenia and the dosage of clozapine being increased up to $450 \mathrm{mg} /$ day. Even if this strategy should remain exceptional, it offers an alternative to the interruption of treatment with clozapine in some of the most severe cases.

\section{Declaration of interest}

None with respect to Novartis (manufacturers of clozapine). P.B. is on the advisory boards of Pfizer and Eli Lilly, and has received grants from Pfizer, Lundbeck, AstraZeneca and Aventis, who have interests in the manufacture of antipsychotics.

Sperner-Unterweger, B., Czeipek, I., Gaggl, S. et al (1998) Treatment of severe clozapine-induced neutropenia with granulocyte colony-stimulating factor (G-CSF). Remission despite continuous treatment with clozapine. British Journal of Psychiatry, 172, 82-84.

Young, C. R., Bowers, M. B. \& Mazure, C. M. (1998) Management of the adverse effects of clozapine. Schizophrenia Bulletin, 24, 38I-390.

\section{P. Conus, N. Nanzer, P. Baumann}

Departement universitaire de psychiatrie adulte, CH-I008 Prilly-Lausanne, Switzerland

\section{One hundred years ago}

\section{The Medico-Psychological Association of Great Britain and Ireland}

THE Medico-Psychological Association of Great Britain and Ireland held a general meeting on Nov. 21st at 11, Chandosstreet, W., which was presided over by Dr. Fletcher Beach and was numerously attended. The meeting began at four and lasted for nearly three hours, three papers, with interesting discussions on each, being read in that time. The first paper was on Mental Disorders dependent on Toxæmias, by Sir Dyce Duckworth, and will be found printed in full at p. 1475 of this issue of THE LANCET. Our report of the discussions and of the other papers will 